University of Wollongong

Research Online

Faculty of Engineering and Information

Faculty of Engineering and Information

Sciences - Papers: Part B

Sciences

2017

\title{
Thermal characterization of lauric acid and stearic acid binary eutectic mixture in latent heat thermal storage systems with tube and fins
}

\author{
Lei Ding \\ University of Wollongong, Id477@uowmail.edu.au \\ Lixiong Wang \\ Tianjin University \\ Georgios Kokogiannakis \\ University of Wollongong, gkg@uow.edu.au \\ Yajun Lu \\ North China University of Water Resources and Electric Power \\ Weibing Zhou \\ Wuhan University of Technology
}

Follow this and additional works at: https://ro.uow.edu.au/eispapers1

Part of the Engineering Commons, and the Science and Technology Studies Commons

Research Online is the open access institutional repository for the University of Wollongong. For further information contact the UOW Library: research-pubs@uow.edu.au 


\title{
Thermal characterization of lauric acid and stearic acid binary eutectic mixture in latent heat thermal storage systems with tube and fins
}

\author{
Abstract \\ In order to obtain the suitable phase change material (PCM) with low phase change temperature and \\ improve its heat transfer rate, experimental investigation was conducted. Firstly, different mass ratios of \\ lauric acid (LA) and stearic acid(SA) eutectic mixtures were prepared and characterized by differential \\ scanning calorimetry (DSC). Then, the performance of eutectic mixture during charging process under \\ different fin widths in vertical condition, and performance during charging and discharging processes \\ under different inlet temperature heat transfer fluid (HTF) in horizontal condition were investigated, \\ respectively. The results revealed that the LA-SA eutectic mixture had the suitable phase change \\ temperature and desired latent heat for low-temperature water floor heating system. Wide fins and high \\ inlet temperature HTF significantly enhanced the transfer rate and decreased the melting time.

\section{Disciplines} \\ Engineering | Science and Technology Studies

\section{Publication Details} \\ Ding, L., Wang, L., Kokogiannakis, G., Lu, Y. \& Zhou, W. (2017). Thermal characterization of lauric acid and \\ stearic acid binary eutectic mixture in latent heat thermal storage systems with tube and fins. Journal \\ Wuhan University of Technology, Materials Science Edition, 32 (4), 753-759.
}




\title{
Thermal characterization of lauric acid and
}

\section{stearic acid binary eutectic mixture in latent heat thermal storage}

\author{
systems with tube and fins \\ Lei Ding ${ }^{a, b}$, Lixiong Wang $^{a}$, Georgios Kokogiannakis ${ }^{b}$, Yajun $L^{c}{ }^{c}$, Weibing Zhou ${ }^{d^{*}}$ \\ a. School of Architecture, Tianjin University, Tianjin 300072, China ; b. Sustainable Buildings Research Centre, University of Wollongong, \\ Wollongong 2500, Australia; c. School of Architecture, North China University of Water Resources and Electric Power, Zhengzhou \\ 450045, China; d. School of Materials Science and Engineering, Wuhan University of Technology, Wuhan 430070, China
}

Abstract: In order to obtain the suitable phase change material (PCM) with low phase change temperature and improve its heat transfer rate, experimental investigation was conducted in this study. Firstly, different mass ratio of lauric acid(LA) and stearic acid(SA) eutectic mixture were prepared and characterized by differential scanning calorimetry (DSC).Then, the performance of eutectic mixture during charging process under different fin width in vertical condition, and performance during charging and discharging processes under different inlet temperature heat transfer fluid(HTF) in horizontal condition were investigated respectively. The results revealed that the LA-SA eutectic mixture had the suitable phase change temperature and desired latent heat for low-temperature water floor heating system. Wide fins and high inlet temperature HTF significantly enhanced the transfer rate and decreased the melting time.

Key words: LA-SA binary eutectic mixture, Thermal properties, Heat exchanger, Heat transfer mechanism

\section{Introduction}

In China, building energy consumption doubled from 1998 to 2009, and the share of total energy consumption in buildings has been increased from $20 \%$ to $40 \%{ }^{[1]}$. Phase change materials (PCM) that can absorb, store and release heat according to the surrounding environmental conditions provide an alternative for reducing peak cooling loads and improving indoor thermal comfort.

PCM can be widely applied in actual projects, such as solar energy systems ${ }^{[2,3]}$, thermal storage of building ${ }^{[4]}{ }^{[5]}$ and recycling the industrial waste heat ${ }^{[6]}$, and so on.

At present, a large number of inorganic, organic and their mixtures PCMs have been studied $^{[7]}$.Among all investigated PCMs, the organic fatty acids mixtures have good thermal and chemical stability, small volume change, self-nucleating behavior and low sub-cooling. These make them a preferred thermal storage material in building application due to congruent melting, good chemical stability and non-toxicity. Furthermore, fatty acids have less environmental impacts than other PCMs because they are derived from common vegetable and animal oils ${ }^{[8,9]}$.However, the higher phase change temperature exceeds the human body comfort range and lower thermal conductivity $(0.2 \sim 0.3 \mathrm{~W} / \mathrm{m} \mathrm{k})$ reduce heat transfer efficiency.

Lei Ding (丁否): Ph D; E-mail: ld477@uowmail.edu.au

*Corresponding author: zhou weibing (周卫兵), associate professor, Ph D; Tel:+86 13545195411, fax:+86 87879468

E-mail address: jsyczwb@whut.edu.cn

Funded by the Key Project of National Natural Science Funds (Grant No. 51432007) and the Science and Technology Support Program of Hubei Province (Grant No.2014BAA134 and 2015BAA107). 
In previous studies where fatty acids have been used as PCMs, it was found that two or more fatty acids can be mixed to form an eutectic mixture with a lower phase change temperature and the same stability of a single component. Eutectic mixtures of fatty acids as PCMs have a wider phase change temperature range and thus they have also started to be used more frequently in engineering applications .San et al. ${ }^{[10]}$ investigated the possibilities of combining stearic acid (SA), lauric acid (LA), myristic acid (MA), and palmitic acid (PA) and they found that the melting temperatures of the binary systems are lower than those of the single acids. They also found that there are no major changes in the melting temperatures and the latent heat of fusion of these materials after accelerated thermal cycle tests. Fauzi et al. ${ }^{[11]}$ studied myristic acid/palmitic acid/sodium myristate (MA/PA/SM) and myristic acid/palmitic acid/sodium palmitate (MA/PA/SP), by using a thermal cycling test setup. It was found that the chemical bonding structures of these eutectic PCMs show no degradation and their thermal performance shows a good stability after 3600 thermal cycles.

The low thermal conductivity is another drawback of the fatty acid PCMs. In order to improve the heat transfer, various approaches have been developed and the relevant literature has been summarized in this paragraph. Sarı et al. ${ }^{[10,12,13]}$ studied the thermal properties and phase change stability of MA, PA and SA as PCMs through experiments. The PCMs were filled in the ring cavities of two concentric circular tubes and hot and cold water was used to heat and cool the PCMs, respectively. The experimental results show that the melting stability of the PCMs was better in the radial direction than that in the axial direction. In the melting process, the heat convection in the liquid phase played an important role. Sharma et al. ${ }^{[14]}$ studied the effect of thermal conductivity and thermal capacity of fatty acids, the thermal conductivity of heat exchanger materials and their effect on melt fraction. Hamada et al. ${ }^{[15]}$ inserted carbon fiber brushes to improve the heat transfer rates of phase change materials in the heat thermal energy storage tanks, which were used in an air conditioning system of a building. Kurnia et al. ${ }^{[16]}$ analyzed numerically the heat transfer rate of PCM thermal energy storage devices with different configurations on cyclic charging and discharging processes and used multiple PCMs arrangement to further enhance their thermal performance. Tay et al. ${ }^{[17]}$ constructed a new heat transfer enhancement device; a tube-in-tank thermal storage, increasing the temperature gradients during the melting process significantly. Abduljalil et al. ${ }^{[18]}$ experimentally investigated the charging and discharging process in a triplex tube heat exchanger with internal and external fins. Tiariet al. ${ }^{[8]}$ investigated numerically the effect of heat pipe spacing, length and number of fins and the influence of natural convection on the thermal response of the thermal energy storage unit. Lv et al. $^{[9]}$ investigated experimentally the thermal conductivity efficiency of Polyethylene glycol (PEG) which was added the different mass fraction of expanded graphite (EG). Yang et $\mathrm{al}^{[19]}$. prepared a myristic-palmitic-stearic acid with expanded graphite composite (MA-PA-SA/EG) PCM and conducted a thermal and chemical stability test. The results indicated the prepared composite PCM has improved properties, and the conductivity of the composite PCM was measured as $2.51 \mathrm{~W} / \mathrm{m}$ $\mathrm{K}$, which is much higher than that of MA-PA-SA.

This research focuses on a binary eutectic PCM for thermal energy storage which is composed of lauric acid and stearic acid(LA-SA) and, as it will be shown in Section 2, it is positioned vertically and horizontally in a heat exchanger. Different mass ratios of LA-SA eutectic mixtures were prepared, and their thermal properties were firstly characterized by DSC. Then, an experiment was conducted to investigate the effect of the fin width on the heat transfer efficiency 
when the heat exchanger is positioned vertically. Finally, the experiment was repeated by changing the inlet temperature of the HTF in the heat exchanger and positioning the heat exchanger horizontally in order to study the potential differences on heat transfer performance.

\section{Experimental procedures}

\subsection{Materials and thermal properties of LA-SA eutectic mixture}

Lauric acid and stearic acid obtained from Jiehui Chemical Co., Ltd., China were used as the phase change materials. The following six eutectic mixture samples with different mass ratios of LA and SA (LA:SA) were prepared: (70:30), (72:28), (74:26), (75.5:24.5), (78:22) and (80:20). The preparation process involved pouring the mixture samples into $500 \mathrm{ml}$ beakers separately, then putting the beaker into a thermostatic water bath at $70^{\circ} \mathrm{C}$, and finally using a magnetic stirrer at 400rpm/min to stir the mixture for $45 \mathrm{~min}$.

The phase change temperature and latent heat of the six eutectic mixture samples were investigated by using a differential scanning calorimeter (PE: Pyris-1 USA) at $10^{\circ} \mathrm{C} / \mathrm{min}$, under a constant stream of argon, at a flow rate of $50 \mathrm{~mL} / \mathrm{min}$. The phase change enthalpy and temperature measurements had an accuracy within $\pm 5 \%$ and $\pm 0.2{ }^{\circ} \mathrm{C}$, respectively. The DSC instrument was calibrated with indium as a standard reference material.

\subsection{Experimental devices and methodology}

Experimental studies were conducted to reveal the heat transfer performance of the LA-SA binary PCM in a heat exchanger system. The schematic of the experimental system is shown in Fig.1, which was composed of a sealed shell filled with PCM, an aluminum finned tube passing through the shell, water tank with flow meter supplying constant heat transfer fluid (HTF), and a data logger. The dimensions of the heat exchanger units in vertical and horizontal position was shown in Fig.2. In the heat exchanger system, thermocouples(K-type, copper-constantan, $1.5 \mathrm{~mm}$ diameter and accuracy $\pm 0.2 \mathrm{~K}$ ) were used to measure the temperature evolution. The position of the thermocouples is shown in Fig.1, and the figure also demonstrates the dimension of the heat exchanger and fined tube.

In our heat transfer experiment, two experimental procedures were conducted as follows:

1) In the first procedure, the heat exchanger was positioned vertically, with fin width being varied as $0 \mathrm{~mm}$ (no fins), $10 \mathrm{~mm}, 20 \mathrm{~mm}$, and $30 \mathrm{~mm}$. Heat transfer experiments were conducted to analysis the heat transfer process of binary organic PCMs and quantify the effect of the heat exchange area on the heat storage of PCM.

2) In the second procedure, the heat exchanger was positioned horizontally, with the inlet temperature being varied as $50^{\circ} \mathrm{C}, 60^{\circ} \mathrm{C}$ and $70^{\circ} \mathrm{C}$. Complete charging and natural discharging experiments were conducted for 10 hours to investigate the heat transfer mechanism of binary organic PCMs and the effect of that the HTF temperature has on heat storage of PCM. 


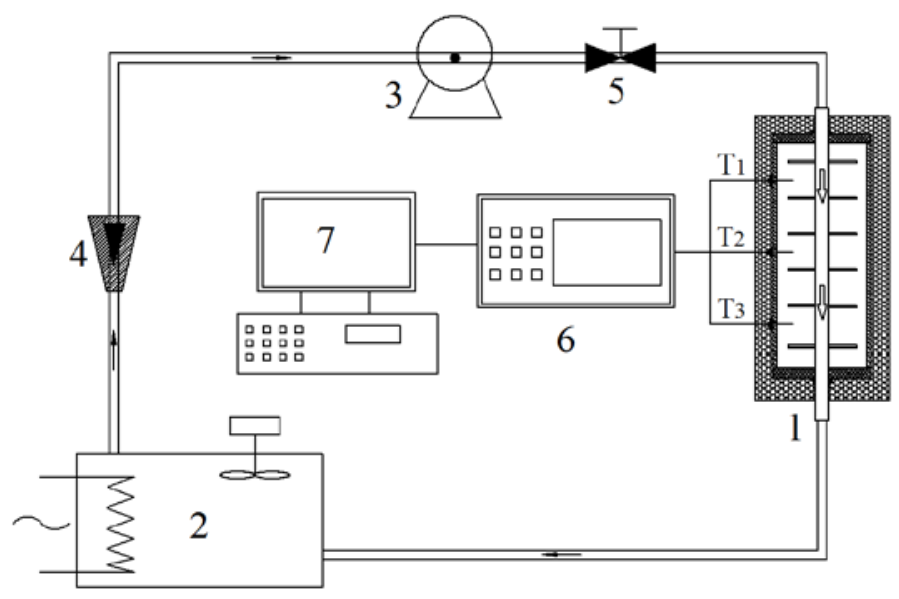

(a)

Fig.1. Schematic of the experimental step:1-Heat exchanger, 2-Constant temperature water tank, 3-Water pump, 4-Flow meter, 5-Valve, 6-Data logger, 7-Computer
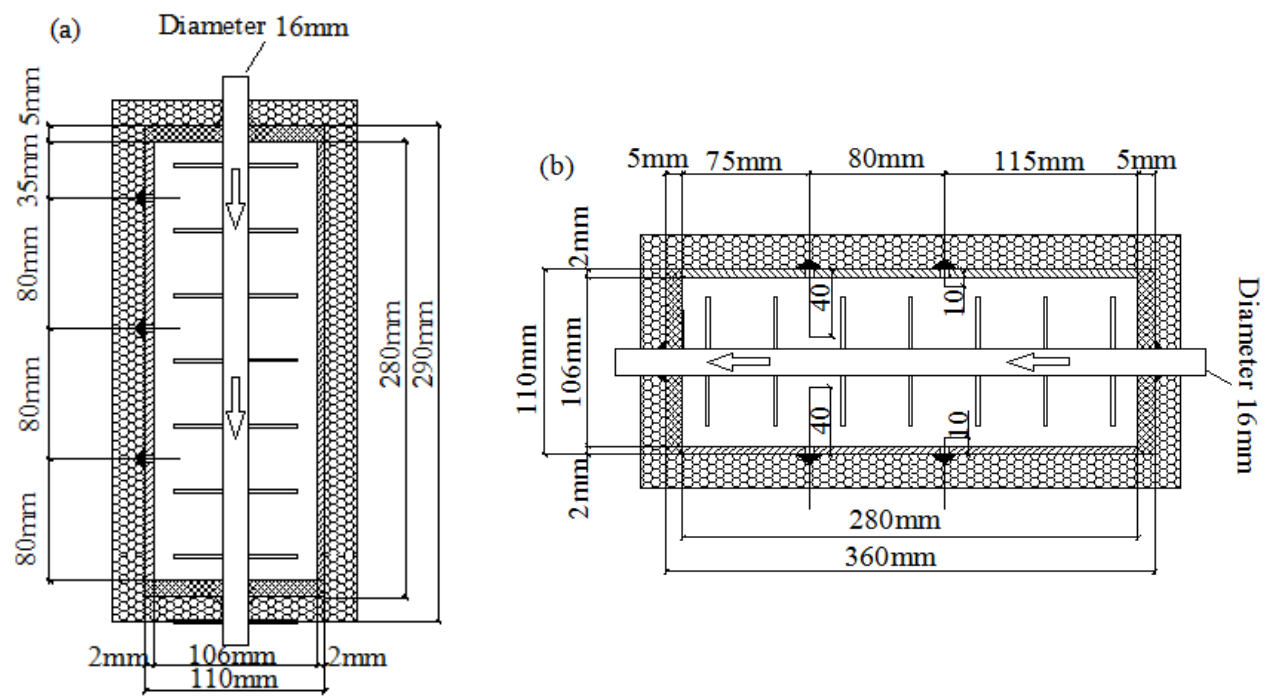

Fig.2 Dimensions of the heat exchanger units: (a)the heat exchanger units in vertical condition;

(b)the heat exchanger units in horizontal condition

\section{Result and discussion}

\subsection{Properties of the LA-SA eutectic mixture}

Fig.3 reveals the DSC curves of pure LA, SA and LA-SA eutectic mixture with different mass ratio during charging and discharging process, and Table 1 presents the corresponding latent heat fusion and phase change temperature values from the measurements. 


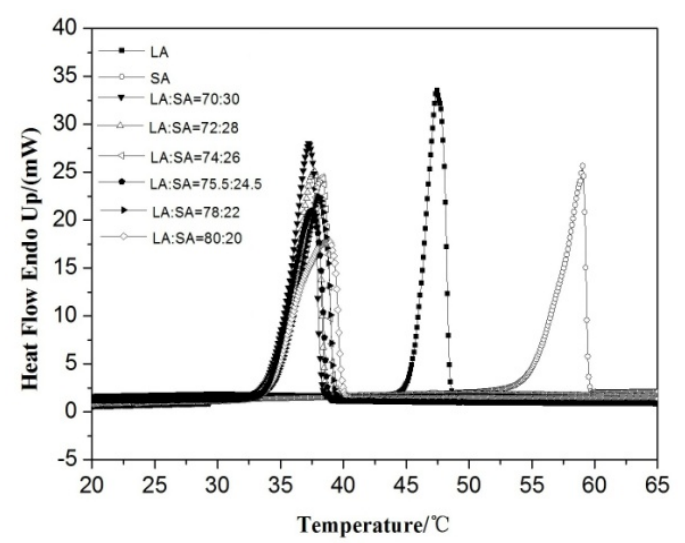

(a)

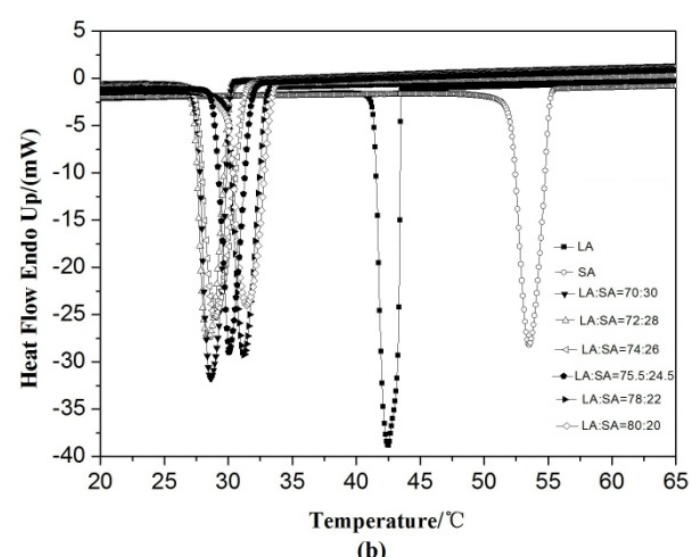

(b)

Fig.3 DSC curves of pure LA, SA and LA-SA eutectic mixture with different mass ratio:

(a) charging process; (b)discharging process

Table 1 Latent heat and phase change temperature of LA-SA eutectic mixture

\begin{tabular}{ccccccccc}
\hline & \multicolumn{3}{c}{ Charging process } & \multicolumn{3}{c}{ Discharging process } \\
\cline { 2 - 9 } Specimen & $\begin{array}{c}\text { DeltaH/ } \\
(\mathrm{J} / \mathrm{g})\end{array}$ & $\begin{array}{c}\text { Onset/ } \\
\left({ }^{\circ} \mathrm{C}\right)\end{array}$ & $\begin{array}{c}\text { Peak/ } \\
\left({ }^{\circ} \mathrm{C}\right)\end{array}$ & $\begin{array}{c}\text { End/ } \\
\left({ }^{\circ} \mathrm{C}\right)\end{array}$ & $\begin{array}{c}\text { DeltaH/ } \\
(\mathrm{J} / \mathrm{g})\end{array}$ & $\begin{array}{c}\text { Onset/ } \\
\left({ }^{\circ} \mathrm{C}\right)\end{array}$ & $\begin{array}{c}\text { Peak/ } \\
\left({ }^{\circ} \mathrm{C}\right)\end{array}$ & $\begin{array}{c}\text { End/ } \\
\left({ }^{\circ} \mathrm{C}\right)\end{array}$ \\
\hline LA & 185.24 & 45.60 & 47.71 & 48.48 & -185.32 & 43.56 & 42.52 & 41.42 \\
SA & 187.35 & 56.16 & 59.02 & 59.50 & -183.28 & 55.09 & 53.52 & 52.04 \\
LA:SA(70:30) & 165.45 & 34.71 & 37.15 & 38.15 & -149.67 & 29.97 & 28.59 & 27.47 \\
LA:SA(72:28) & 166.69 & 35.02 & 37.63 & 38.52 & -149.73 & 29.93 & 28.44 & 27.25 \\
LA:SA(74:26) & 168.69 & 34.77 & 38.09 & 39.00 & -153.07 & 31.28 & 29.04 & 27.58 \\
LA:SA(75.5:24.5) & 167.30 & 34.16 & 37.48 & 38.72 & -150.78 & 31.81 & 30.14 & 28.94 \\
LA:SA(78:22) & 169.45 & 34.92 & 38.01 & 39.20 & -157.07 & 32.89 & 31.23 & 29.93 \\
LA:SA(80: 20) & 168.91 & 34.33 & 39.03 & 39.97 & -156.21 & 33.32 & 31.46 & 29.93 \\
\hline
\end{tabular}

The DSC results revealed that the melting temperature of pure LA and SA were $45.6^{\circ} \mathrm{C}$ and $56.16^{\circ} \mathrm{C}$, respectively. Such temperatures are higher than the usual temperatures that are occurring in the built environment. However, for the LA-SA binary eutectic mixtures, the melting temperature reduced significantly (to approximately $34-35^{\circ} \mathrm{C}$ ) and without measuring a significant change of the melting latent heat(Table 1).The reduced melting temperature makes the resulted PCM suitable for low-temperature water floor heating systems, which often operate with temperatures of approximately $45 / 25-35^{\circ} \mathrm{C}$ (supply/return temperatures) ${ }^{[20]}$. The similar characteristics of solidification temperature and enthalpy can also be observed from DSC results during the freezing process. Furthermore, the sub-cooling phenomenon of the binary mixture weakens with the mass increase of LA as shown the DSC results presented in Table 1 . When the mass fraction of LA: SA was 75.5:24.5, the melting and solidification temperature of binary mixture were $34.16^{\circ} \mathrm{C}$ and $31.81^{\circ} \mathrm{C}$, and melting and solidification latent heat were $167.30 \mathrm{~J} / \mathrm{g}$ and $150.78 \mathrm{~J} / \mathrm{g}$, respectively. The test results were in accordance with the previous research $^{[21]}$. Therefore, the binary mixture with mass fraction of 75.5:24.5(LA: SA) was employed in the following research.

\subsection{The effect of fin width on charging performance in vertical condition}


In this section, the heat exchanger was placed in vertical position as shown in Fig. 4(e). The experiment was conducted to study the effect of fin width on heat transfer performance.

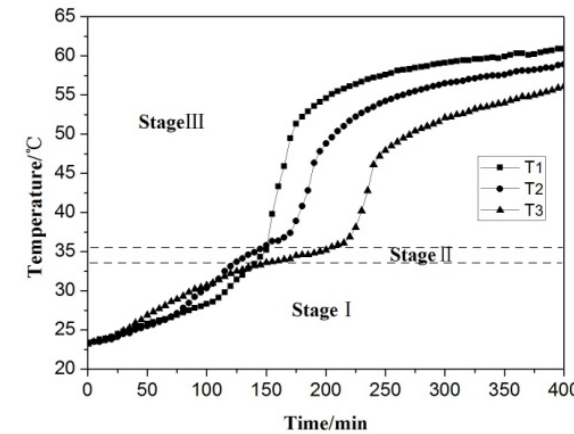

(a)

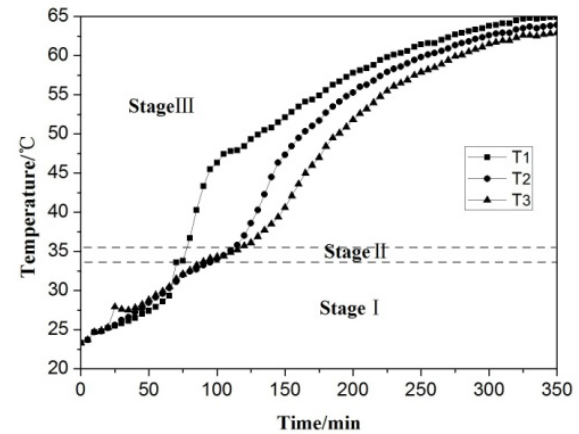

(c)

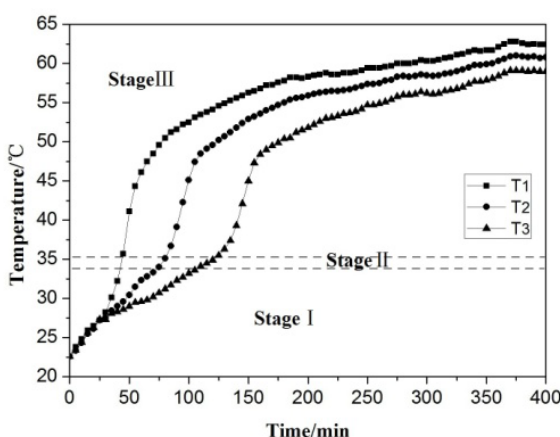

(b)

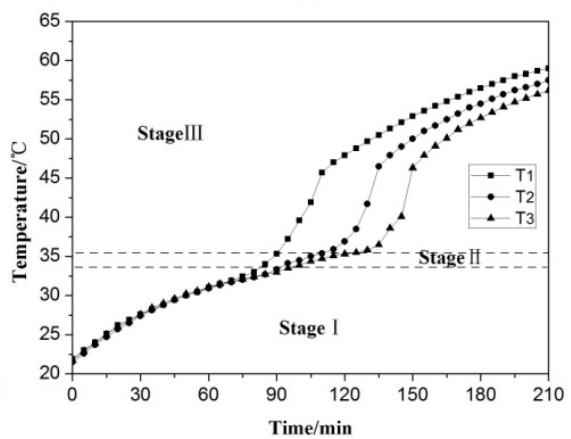

(d)

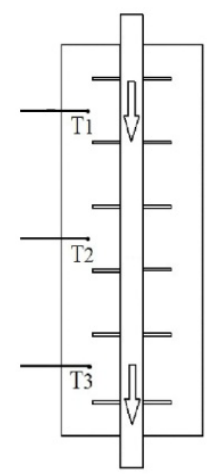

(e)

Fig. 4 Temperature evolutions of the heat storage unit with different fin width: (a) 00mm,

(b) $10 \mathrm{~mm}$, (c) $20 \mathrm{~mm}$, (d) $30 \mathrm{~mm}$; (e) the location of the tested points

Fig.4 illustrates the temperature curves of LA-SA eutectic mixture during charging process with fin width of $0 \mathrm{~mm}, 10 \mathrm{~mm}, 20 \mathrm{~mm}$ and $30 \mathrm{~mm}$,with and inlet $\mathrm{HTF}$ temperature of $70^{\circ} \mathrm{C}$ and $\mathrm{HTF}$ velocity of $1.5 \mathrm{~L} / \mathrm{min}$. The temperature curves are divided in three stages: solid sensible heating (stage I), phase change (stage II) and liquid sensible heating (stage III). In solid sensible heating process, the temperature of all tested points does not reach the melting point and all three temperature curves follow a similar trend, with temperature increasing slowly over time. After the phase change process is completed, the temperature increases rapidly and the tested point located at the higher part of the heat exchanger has the higher temperature $\left(T_{1}>T_{2}>T_{3}\right)$. Finally, there is a slower temperature increase at the three tested points, and as the progresses all three temperature curves are approaching each other.

The charging process above can be explained as follows: At solid sensible heating stage (stage I), the heat exchanger is filled with solid PCM which has low thermal conductivity, and as a result the temperature increases slowly. At phase change stage (stage II), the PCM reaches to the melting point, the solid PCM around the heat transfer tube melts, with the PCM around the upper test pointed $\left(T_{1}\right)$ melting first, followed by the PCM at the lower parts $\left(T_{2}\right.$ and $T_{3}$ ). At the liquid heating stage (stage III), the higher temperature liquid PCM has lower density moves, above the solid PCM surface which has higher density. Therefore, during the early process of stage III, the temperature of test point $T_{1}$ rises faster than the temperature at test point $T_{2}$, which in turn rises faster than the temperature at test point $\mathrm{T}_{3}$. During the last part of stage III, the temperature difference in heat exchanger between the upper part and the lower part is relatively small, which leads to natural convection vanishing gradually and losing its dominance on enhancing the heat transfer. 
When comparing the temperature curves of the four diagrams as shown in Fig.4(a, b, c, d), it can be seen that fin width is an important factor and has great influence on heat transfer performance. For test point 3, for example, which is positioned at the bottom of the heat exchanger, it can be observed that the heating time of the solid sensible heating stage requires $175 \mathrm{~min}$, $130 \mathrm{~min}, 125 \mathrm{~min}$ and $110 \mathrm{~min}$ when fin width is $0 \mathrm{~mm}, 10 \mathrm{~mm}$, $20 \mathrm{~mm}$ and $30 \mathrm{~mm}$, respectively. Similarly, the time required for test $\mathrm{T}_{3}$ to $60^{\circ} \mathrm{C}$ decreases significantly with the increase of fin width. It has been therefore shown that fin width extends the heat transfer area in the heat exchanger, which significantly enhance the heat transfer efficiency of the PCMs.

\subsection{The effect of inlet temperature in horizontal condition}

In this section, the heat exchanger is positioned horizontally, and inlet temperatures varied as $50^{\circ} \mathrm{C}, 60^{\circ} \mathrm{C}$ and $70^{\circ} \mathrm{C}$. The fin width used was $30 \mathrm{~mm}$ and the HTF velocity was $1.5 \mathrm{~L} / \mathrm{min}$. Measurements were therefore conducted to quantify the effect of inlet temperatures during the charging and natural discharging processes.

Fig.5(a, b, c) illustrates the temperature evolutions of PCM. It can be seen that the temperature curves can be divided into two parts: charging process and natural discharging process. During the charging process as shown in Fig.5, the temperature of the tested points in the upper part of the heat exchanger are usually higher than that in the lower part $\left(T_{2}>T_{1}>T_{4}>T_{3}\right)$. The corresponding tested points $\left(\left(T_{2}, T_{4}\right),\left(T_{1}, T_{3}\right)\right)$ are positioned at an equal distance from the tube, but the temperature of $\left(T_{2}, T_{1}\right)$ increases more rapidly than that of $\left(T_{4}, T_{3}\right)$, which is attributed to natural convection that drives the higher temperature liquid PCM to move above the lower temperature solid PCM.

During the discharging process, the temperature curves of the four tested points drop rapidly to the melting point by following approximately the same trend with each other. The temperature variations of the discharging process are very different to the charging process. During discharging, the temperature of each point decreases gradually until it becomes approximately constant around the solidification points. Hence, it can be concluded that natural convection dominates the charging process and thermal conduction plays the most important role during the discharging process. 


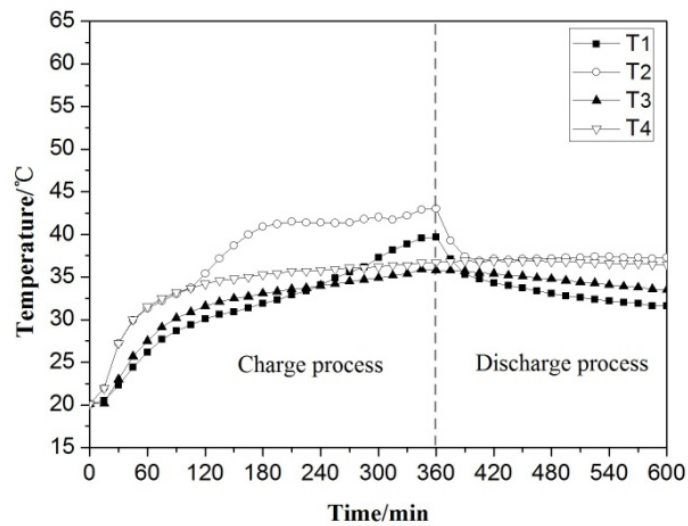

(a)

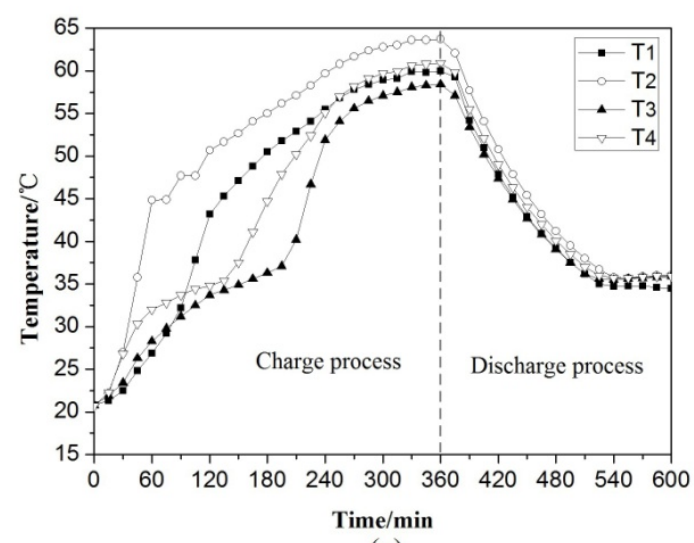

(c)

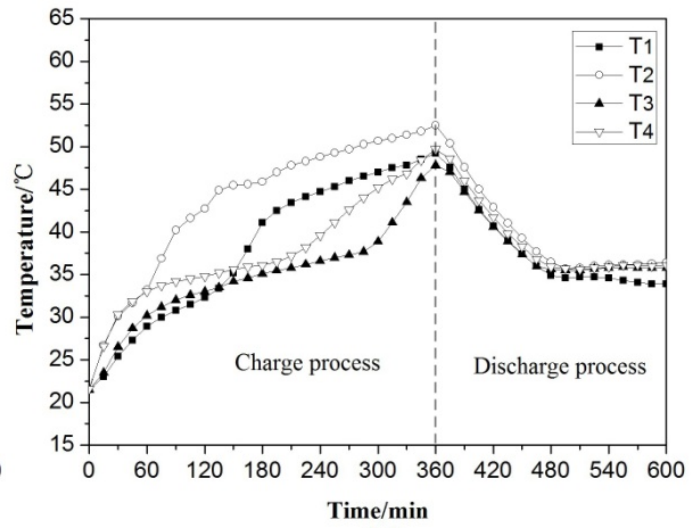

(b)

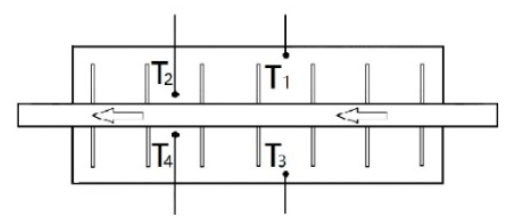

(d)

Fig. 5 Temperature evolutions of $6 \mathrm{~h}$ charging and $4 \mathrm{~h}$ natural discharging with different inlet temperature: (a) $50^{\circ} \mathrm{C}$, (b) $60^{\circ} \mathrm{C}$, (c) $70^{\circ} \mathrm{C}$; (d) the location of the tested points

HTF temperature affected the temperature evolution significantly. A HTF temperature of $50^{\circ} \mathrm{C}$ melts the PCM ineffectively as shown in Fig.5(a), with only one test point temperature $\left(\mathrm{T}_{2}\right)$ being increased rapidly after reaching the melting point, while the temperature of the lower two test points $\left(\mathrm{T}_{3}\right.$ and $\left.\mathrm{T}_{4}\right)$ fails to exceed the melting point. $\mathrm{HTF}$ temperatures of $60^{\circ} \mathrm{C}$ and $70^{\circ} \mathrm{C}$ melt the PCM effectively as shown in Fig.4(b, c), where it can be seen that the temperature of all four test points increased rapidly after reaching the melting point. For test point 2,for example, after $6 \mathrm{~h}$ of heating with an inlet temperature of $50^{\circ} \mathrm{C}$ the test point temperature is $42.5^{\circ} \mathrm{C}$.On the other hand, when inlet temperature was $60^{\circ} \mathrm{C}$ and $70^{\circ} \mathrm{C}$ for $6 \mathrm{~h}$ of heating, the test point temperature $\left(\mathrm{T}_{2}\right)$ was $53^{\circ} \mathrm{C}$ and $64^{\circ} \mathrm{Crespectively,} \mathrm{a} 24.7 \%$ and $50.6 \%$ increase respectively when compared with the case of $50^{\circ} \mathrm{C}$ inlet temperature. Hence, it was shown that the inlet temperature has significantly enhanced the heat transfer efficiency in the heat exchanger with the PCM.

\section{Conclusions}

In this study, characterization of binary organic PCM was characterized and two heat transfer experiments were conducted. Three conclusions can be drawn as follows from the results obtained:

a) DSC results show that when comparing with pure LA and SA, the melting and solidification temperature of LA-SA eutectic mixtures can be significantly reduced to values that are more 
useful for applications in buildings. Meanwhile, the latent heat of the LA-SA eutectic mixtures is not significantly less than the latent heat of pure LA and SA.

b) The natural convection existed both in charging and discharging process. For the charging process, natural convection play an important role in heat transfer which can reduce the charging time, but natural convection in discharging process is much weaker than that in charging process.

c) During the heat transfer process in a heat exchanger that contains a LA-SA binary eutectic mixture, increasing the fin width to expand the heat transfer area improves the heat transfer efficiency and significantly decreases the melting time.

\section{Reference}

[1] X. Kong, S. Lu, Y. Wu, A review of building energy efficiency in China during "Eleventh Five-Year Plan” period, Energ Policy, 41 (2012) 624-635.

[2] H. Singh, Gagandeep, K. Saini, A. Yadav, Experimental comparison of different heat transfer fluid for thermal performance of a solar cooker based on evacuated tube collector, Environ Dev Sustain, 17 (3) (2015) 497-511.

[3] A. Reyes, D. Negrete, A. Mahn, F. Sepulveda, Design and evaluation of a heat exchanger that uses paraffin wax and recycled materials as solar energy accumulator, Energy Conversion and Management, 88 (2014) 391-398.

[4] C.B. Zhang, Y.P. Chen, L.Y. Wu, M.H. Shi, Thermal response of brick wall filled with phase change materials (PCM) under fluctuating outdoor temperatures, Energ Buildings, 43 (12) (2011) 3514-3520.

[5] A.M. Khudhair, M.M. Farid, A review on energy conservation in building applications with thermal storage by latent heat using phase change materials, Energy Conversion and Management, 45 (2) (2004) 263-275.

[6] Y.Q. Zhang, Y.T. Wu, G.D. Xia, C.F. Ma, W.N. Ji, S.W. Liu, K. Yang, F.B. Yang, Development and experimental study on organic Rankine cycle system with single-screw expander for waste heat recovery from exhaust of diesel engine, Energy, 77 (2014) 499-508.

[7] Y. Yuan, N. Zhang, W. Tao, X. Cao, Y. He, Fatty acids as phase change materials: A review, Renewable and Sustainable Energy Reviews, 29 (2014) 482-498.

[8] S. Tiari, S. Qiu, M. Mahdavi, Numerical study of finned heat pipe-assisted thermal energy storage system with high temperature phase change material, Energy Conversion and Management, 89 (2015) 833-842.

[9] Y. Lv, W. Zhou, W. Jin, Experimental and numerical study on thermal energy storage of polyethylene glycol/expanded graphite composite phase change material, Energy and Buildings, 111 (2016) 242-252.

[10] A. Sarı, H. Sarı, A. Önal, Thermal properties and thermal reliability of eutectic mixtures of some fatty acids as latent heat storage materials, Energy Conversion and Management, 45 (3) (2004) 365-376.

[11] H. Fauzi, H.S.C. Metselaar, T.M.I. Mahlia, M. Silakhori, H.C. Ong, Thermal characteristic reliability of fatty acid binary mixtures as phase change materials (PCMs) for thermal energy storage applications, Applied Thermal Engineering, 80 (2015) 127-131.

[12] A. Sarı, K. Kaygusuz, Thermal performance of myristic acid as a phase change material for energy storage application, Renew Energ, 24 (2) (2001) 303-317.

[13] A. Sari, K. Kaygusuz, Thermal performance of palmitic acid as a phase change energy storage 
material, Energy Conversion and Management, 43 (6) (2002) 863-876.

[14] A. Sharma, L.D. Won, D. Buddhi, J.U. Park, Numerical heat transfer studies of the fatty acids for different heat exchanger materials on the performance of a latent heat storage system, Renew Energ, 30 (14) (2005) 2179-2187.

[15] Y. Hamada, J. Fukai, Latent heat thermal energy storage tanks for space heating of buildings: Comparison between calculations and experiments, Energy Conversion and Management, 46 (20) (2005) 3221-3235.

[16] J.C. Kurnia, A.P. Sasmito, S.V. Jangam, A.S. Mujumdar, Improved design for heat transfer performance of a novel phase change material (PCM) thermal energy storage (TES), Applied Thermal Engineering, 50 (1) (2013) 896-907.

[17] N.H.S. Tay, F. Bruno, M. Belusko, Experimental investigation of dynamic melting in a tube-in-tank PCM system, Appl Energ, 104 (2013) 137-148.

[18] A.A. Al-Abidi, S. Mat, K. Sopian, M.Y. Sulaiman, A.T. Mohammad, Experimental study of melting and solidification of PCM in a triplex tube heat exchanger with fins, Energy and Buildings, 68, Part A (2014) 33-41.

[19] X. Yang, Y. Yuan, N. Zhang, X. Cao, C. Liu, Preparation and properties of myristic-palmitic-stearic acid/expanded graphite composites as phase change materials for energy storage, Solar Energy, 99 (2014) 259-266.

[20] J.A. Myhren, S. Holmberg, Flow patterns and thermal comfort in a room with panel, floor and wall heating, Energy and Buildings, 40 (4) (2008) 524-536.

[21] G. Baran, A. Sari, Phase change and heat transfer characteristics of a eutectic mixture of palmitic and stearic acids as PCM in a latent heat storage system, Energy Conversion and Management, 44 (20) (2003) 3227-3246. 
作者简介: 丁否（1978.4-）, 男, 山东省, 聊城市人, 中级工程师, 博士, E-mail: ld477@uowmail.edu.au 基金项目: 国家自然科学基金 (Grant No. 51432007) 和 湖北省科技支撑技术 (Grant No.2014BAA134 and 2015BAA107).

通讯作者: 1.周卫兵；2.武汉理工大学 (430070)； 3.邮箱: jsyczwb@whut.edu.cn 电话: 13545195411。 